\title{
(RE) DESCOBERTA DE ESPERANÇA NA FAMÍLIA DA CRIANÇA COM DOENÇA CRÔNICA ATRAVÉS DO GENOGRAMA E ECOMAPA
}

\author{
Zaida Borges Charepe ${ }^{1}$, Maria Henriqueta de Jesus Silva Figueiredo², Margarida Maria da Silva Vieira3 , \\ Luís Miguel Vicente Afonso Neto ${ }^{4}$
}

\footnotetext{
${ }^{1}$ Doutoranda em Enfermagem na Universidade Católica Portuguesa. Docente no Instituto de Ciências da Saúde da Universidade Católica Portuguesa. Portugal. E-mail: zaidacharepe@ics.lisboa.ucp.pt

${ }^{2}$ Doutora em Ciências de Enfermagem. Docente na Escola Superior de Enfermagem do Porto. Portugal. E-mail: henriqueta@ esenf.pt

${ }^{3}$ Doutora em Filosofia. Docente no Instituto de Ciências da Saúde da Universidade Católica Portuguesa. Portugal. E-mail: mmvieira@ics.porto.ucp.pt

${ }^{4}$ Doutor em Educação. Docente na Faculdade de Psicologia e de Ciências da Educação da Universidade de Lisboa. Portugal. E-mail: neto@fpce.ul.pt
}

RESUMO: Nos contextos do cuidar da família da criança com doença crônica, vários têm sido os desafios que se colocam às equipes de enfermagem, no âmbito da promoção de esperança, em contexto da avaliação e intervenção familiar. O genograma e ecomapa constituem-se como veículos para uma compreensão mais aprofundada dos vínculos e padrões de interação da família. Pretendemos apresentar a utilização do genograma e ecomapa na identificação dos recursos de esperança junto a mães de crianças com doença crônica. Trata-se de uma investigação qualitativa, onde foram identificados os factores que influenciam a esperança nos grupos de ajuda mútua. A colheita de dados foi realizada através de entrevista semi-estruturada a vinte mães, de Julho de 2009 a Junho de 2010. Os resultados permitiram identificar os padrões de interação em esperança, os atributos pessoais dos seus membros, a base espiritual e as memórias moralizantes, possibilitando uma reflexão acerca da rede familiar, como rede de força, resiliência e empowerment.

DESCRITORES: Família. Crianças com deficiência. Confiança. Pesquisa qualitativa.

\section{(RE) DISCOVERING HOPE IN FAMILIES OF CHILDREN WITH CHRONIC DISEASE THROUGH GENOGRAM AND ECOMAP}

\begin{abstract}
Within the care settings of families of children with chronic diseases, there are challenges nursing teams have to face within the scope of fostering hope with the context of family assessment and intervention. The genogram and the ecomap have become vehicles for a deeper understanding of attachments and family interaction patterns. We propose the utilization of genograms and ecomaps in identifying resources for hope for mothers of children with chronic diseases. This is a qualitative study which identified factors that influence hope in mutual help groups. Data was collected through semi-structured interviews with twenty mothers, carried out from July of 2009 to June of 2010. The results permit the identification of patterns of interaction with hope, the personal attributes of its members, spiritual bases, and moralizing memories, enabling reflexion on the family network as a network of strength, resilience, and empowerment.
\end{abstract}

DESCRIPTORS: Family. Disabled children. Trust. Qualitative research.

\section{(RE) DESCUBRIMIENTO DE LA ESPERANZA EN LA FAMILIA DEL NIÑO CON ENFERMEDAD CRÓNICA A PARTIR DE GENOGRAMA Y ECOMAPA}

RESUMEN: En el contexto de los cuidados de la familia del niño con enfermedad crónica distintos han sido los retos que se plantean a los equipos de enfermería en el ámbito de la promoción de esperanza en el momento de la evaluación e intervención familiar. El genograma y ecomapa se constituyen en un vehículo para la comprensión más profundizada de los vínculos y de los modelos de interacción de la familia. Tenemos la intención de proponer la construcción de un genograma y ecomapa para identificar los recursos de esperanza con madres de niños con enfermedad crónica. Se trata de una investigación cualitativa, donde se identificaron los factores que influyen en la esperanza en los grupos de ayuda mutua. La recolección de datos se realizó a través de entrevista semi-estructurada de veinte madres, de Julio de 2009 a Junio de 2010. Los resultados muestran los modelos de interacción en esperanza, los atributos personales de sus miembros, la base espiritual y las memorias moralizantes, haciendo posible una reflexión sobre la red familiar, como una red de fuerza, resiliencia y empowerment.

DESCRIPTORES: Familia. Niños con discapacidad. Confianza. Investigación cualitativa. 


\section{INTRODUÇÃO}

Na intervenção em Enfermagem de Saúde Infantil e Pediátrica assume-se espontaneamente, a parceria de cuidados, como uma premissa no cuidar da criança, seus pais e família em circuito de atendimento nos cuidados de saúde.

Da avaliação e intervenção familiar junto aos pais de crianças com doença crônica, o genograma e o ecomapa têm sido valorizados como importantes instrumentos na compreensão dos processos familiares e no reconhecimento do nível de relação estabelecida com os recursos disponíveis na comunidade. Deste modo, os enfermeiros são confrontados a abordarem a família com vista à promoção do seu adequado funcionamento perante a adversidade: impacto da doença crônica, gestão da sua sintomatologia, hospitalização, sofrimento físico, espiritual e/ou ruptura por crise familiar. ${ }^{1}$

No cuidar da criança com doença crônica são depreendidos a interação e os papéis assumidos entre os membros da família, mesmo em domínios da promoção de esperança. Dado que a família confere " $[\ldots]$ diferentes modos de adoecer e de morrer $[\ldots]$.., 2:95 bem como de entender e lidar com a doença e o sofrimento durante o ciclo de vida familiar, podendo influenciar a esperança dos seus membros na família, para além da identificação dos recursos individuais de esperança, deve-se promover a amplificação das histórias de esperança junto do sistema familiar, uma vez que, " $[. .$.$] ao$ testemunharmos, ao ouvirmos e ao elogiarmos é que, muitas vezes, a capacidade de recuperação da família é redescoberta [...]". 2:95

A família pode ser definida de distintas formas: "[...] refere-se a dois ou mais indivíduos, que dependem um do outro para dar apoio emocional, físico e económico [...]". 3:6 Nesse estudo, compreende-se a família como um todo, “[...] considerada como um sistema, pois [...] é composta por objectos e respectivos atributos e relações [...] contém sub-sistemas e é contida por diversos outros sistemas, ou supra-sistemas, todos eles ligados de forma hierarquicamente organizada [...] possui limites ou fronteiras que a distinguem do seu meio". . $^{40}$

Os resultados obtidos pela entrevista a duas mães de crianças com doença crônica visaram a avaliação estrutural da família, estando integrados na etapa exploratória de uma investigação mais abrangente e em curso, realizada no âmbito de uma Tese de Doutoramento em Enfermagem, denominada "O impacto dos grupos de ajuda mútua no desenvolvimento da esperança nos pais de crianças com doença crônica: construção de um modelo de intervenção colaborativa".

Neste contexto, evidenciaram-se as histórias de esperança, pela avaliação estrutural da família, por meio da categorização dos atributos pessoais, relacionamentos e vínculos, alicerçados nos aspectos ontológicos e epistemológicos da esperança.

\section{REFERENCIAL TEÓRICO-METODO- LÓGICO}

O genograma familiar é comumente utilizado na prática de cuidados de enfermagem no âmbito da Enfermagem de Família, Saúde Mental e Enfermagem Comunitária, dentre outros exemplos. A sua origem advém da Terapia Familiar, com a primeira representação de um esquema familiar em três gerações, desenhado por Murray Bowen e respectivos estudantes, na década de 1960/70. ${ }^{5}$ Contudo, só na década de 1980, Murray Bowen e Jack Medalie, viriam a definir de forma mais estruturada, os símbolos do genograma, que são na atualidade amplamente utilizados. ${ }^{6}$

A história da família assume, no genograma familiar, uma tendência para estar " [...] configurada em torno de um problema [...] as famílias tendem a confundir a sua própria história com a história de seus problemas [...]". 6:416 São propostos diferentes adaptações ao genograma familiar, das quais, à título de exemplo, temos o genograma de recursos ${ }^{7}, 0$ genograma de sonhos ${ }^{8}$ e o genograma espiritual. ${ }^{9}$

Os genogramas e os ecomapas espirituais constituem um exemplo do modo como as pessoas, por meio da co-construção de narrativas alusivas às suas histórias espirituais, geram um ambiente propício à edificação de confiança e aliança terapêutica, em reciprocidade com o apoio que lhes é disponibilizado. ${ }^{10}$

O genograma de esperança objetivou identificar os recursos e interações de esperança numa perspectiva inter-geracional, o que implicou que fosse fomentado em contextos de avaliação da esperança no sistema familiar, constituindo-se num recurso colaborativo junto aos pais/família de crianças com doença crônica.

Por quê avaliar a esperança? A esperança é dinâmica, multidimensional, central à vida, altamente personalizada, orientada para o futuro, confere $\mathrm{em}$ powerment e está relacionada com a ajuda externa, o cuidar e o conceito de fé. ${ }^{11}$ É uma dimensão essencial para o êxito no lidar com a doença e a preparação para a morte; ${ }^{12}$ um processo ativo de antecipação, acompanhado pelo desejo e expectativa de um pos- 
sível futuro positivo. ${ }^{13}$ Por outro lado, a esperança é definida pela Classificação Internacional para a Prática de Enfermagem, versão 1.0, como a confiança nos outros, o entusiasmo pela vida, a expressão de razões para viver, a paz interior, o otimismo, o traçar de objetivos e a mobilização de energia. ${ }^{14} \mathrm{~A}$ necessidade de proceder à sua avaliação tem incentivado a construção e a validação de instrumentos de mensuração, de entre os quais, escalas aplicadas nos estudos e programas de intervenção em esperança, em distintos domínios de intervenção.

Descrevemos como vantagens da utilização do genograma de esperança: facilitar a operacionalidade de um plano de intervenção que vise a promoção de esperança e incentivar uma abordagem nas forças e recursos de esperança. Por sua vez, ao nível da representação da estrutura familiar, dos padrões de repetição entre gerações, dos acontecimentos de vida e funcionamento familiar, o genograma de esperança poderá contemplar as informações que forem mais adequadas ao contexto familiar onde se pretende intervir. Deste modo, os pais poderão ter a oportunidade de co-construir a sua história, focalizando-se nas mensagens de esperança, memórias e sentimentos acerca de vivências significativas refletidas na história das suas próprias famílias. ${ }^{15} \mathrm{~A}$ esperança aprende-se e pode ser modelada, quando proveniente de pessoas significativas. ${ }^{15}$

Há necessidade de reciprocidade na utilização de instrumentos para a avaliação da estrutura interna e externa da família, dentre os quais o genograma e o ecomapa constituem-se numa opção importante. Deste modo, quando a família é reconhecida como um recurso, enfatiza-se o "[...] apoio da mesma para a manutenção do tratamento e do bem-estar dos seus integrantes $[\ldots]^{\prime \prime}{ }^{16: 338}$

\section{Genograma de esperança}

A atribuição de novos significados ao genograma, constitui-se numa forma de poder representar os padrões de interação em esperança, os atributos pessoais, as memórias moralizantes e a base espiritual, possíveis de serem identificados em cada membro de uma família. ${ }^{17-18,12}$ Assim, nos padrões de interacção em esperança, foram contemplados os seguintes níveis de relação:

Relação promotora de esperança: quem, no momento atual, lhe transmite esperança e em que situação (relação muito forte na partilha, encorajamento e apoio emocional)? Uma relação promotora de esperança entre os membros de uma família envolve, acima de tudo, as seguintes estra- tégias: apoio emocional, presença efetiva e escuta ativa, demonstração de aceitação incondicional, tolerância e compreensão. ${ }^{19}$

Relação com antecedentes de esperança: quem, no passado, lhe transmitiu esperança e em que situação (relação forte na partilha, encorajamento e apoio emocional)? Os antecedentes de esperança podem incluir eventos significativos (o impacto dos membros da família perante o diagnóstico de doença crônica na criança e/ou a vivência do percurso de tratamento/reabilitação), estímulos stressantes perante a perda de decisões importantes; dificuldade, sofrimento e incerteza. ${ }^{12}$ Uma relação com antecedentes de esperança pode ser igualada a uma relação promotora de esperança. Exemplos de vivências de sofrimento no passado da família, podem significar a identificação mais facilitada de quem é o membro mais bem posicionado para disponibilizar apoio em determinada situação/contexto.

Relação de ameaça à esperança: quem, no momento atual, você identifica como uma ameaça à manutenção da sua esperança (relação unida e conflituosa na partilha, encorajamento e apoio emocional/ abandono e isolamento)? Uma ameaça à esperança é a chave para o sofrimento e um estímulo para a esperança (a espera), incluindo dor, angústia espiritual, fadiga, ansiedade, isolamento social e solidão. ${ }^{12}$

Quanto aos atributos pessoais, memórias moralizantes e base espiritual presentes nos membros que constituem uma determinada família, é atribuída uma codificação específica, à semelhança dos padrões de interação (Anexo 1).

Considera-se como atributos pessoais, as características, a simbologia e/ou uma qualidade considerada positiva. ${ }^{20}$ Os que estão relacionados com a esperança incluem mutualidade e filiação nas relações interpessoais, sendo caracterizados pela coragem e serenidade ${ }^{17}$; força e energia ${ }^{19}$; carinho, orientação para o futuro (estabelecimento e cumprimento de metas) e otimismo. ${ }^{12}$ Estes atributos disponibilizam uma proteção perante o desenvolvimento de atitudes de desespero/desesperança. ${ }^{12}$

As memórias moralizantes, dizem respeito às experiências e/ou vivências relacionadas com recordações positivas. Num estudo desenvolvido com doentes terminais, foram relacionadas com o relembrar da felicidade e atividades positivas que ocorreram no passado, férias e/ou eventos significativos, contribuindo para a renovação do processo de espera. ${ }^{17}$ A espera nos pais/família da criança com doença crônica, traduz-se no que recebem do contexto e no que conseguem colocar em prática, com compromisso, empenho, entrega 
e confiança perante os desafios. ${ }^{21} \mathrm{~A}$ esperança é comunicada de pessoa para pessoa, de geração em geração. ${ }^{15}$ Associando as recordações positivas às histórias de esperança na família, estas podem transformar-se num recurso valioso, pois permitem a descrição de contextos, comportamentos e características das pessoas significativas.

Por fim, a base espiritual está relacionada com a presença de crenças e práticas espirituais e religiosas, identificadas na fé e oração, na participação em atividades religiosas, na manutenção de rituais religiosos específicos, na visita a membros e/ou líderes de uma determinada comunidade espiritual. ${ }^{17}$ Entender a espiritualidade como sendo diferente da religião significa reforçar o significado das atividades diárias bem como o sentido da vida. ${ }^{22}$ Por conseguinte, as crenças " [...] são um ingrediente do que une a família [...]. Os rituais familiares são caminhos[...] para o desenvolvimento, partilha, evolução e passagem para as futuras gerações dos sistemas de crenças com maior importância para a família". 2:57

\section{Ecomapa}

Oecomapa permite analisar previamente " $[. .$. a natureza e a qualidade das relações [...] fortes ou próximas [... $]^{\prime \prime 3: 194}$ que existem entre os pais/família e os recursos da comunidade. Sendo de fácil acesso a sua construção, ressalva-se o seu carácter dinâmico, dado que representa os recursos existentes no momento da sua construção. Em contexto de avaliação da esperança, a mensuração da intensidade dos relacionamentos identificados, foi obtida através da formulação de uma pergunta escala ${ }^{23}$, qual seja: numa escala de 1 a 10, considerando que 10 é o relacionamento que o(a) fez sentir com maior esperança (onde sentiu maior encorajamento) e 1 a sua ausência, que número atribuiria aos relacionamentos que identificou no Ecomapa? Nos relacionamentos que obtiverem um score inferior a 5, é dirigida uma outra questão: o que é que o (a) faz manter esse relacionamento/ligação? Se por outro lado, a pontuação atribuída estiver entre os 5 e os 9: o que será necessário fazer para que a intensidade dos relacionamentos suba meio ponto?

Em continuidade, se com a família existir uma ausência de ligação, ou se o score obtido estiver abaixo dos 5 , sugerimos que não seja realizado o genograma de esperança. A partir da formulação da pergunta escala, é possível efectuar-se uma interpretação dos padrões de interação e recursos de esperança no sistema familiar, baseados em medir o atual nível de progresso rumo a uma solução. ${ }^{24}$
Face ao exposto, esta pesquisa tem como objectivo apresentar a utilização do genograma e de ecomapa na identificação dos recursos de esperança junto a mães de crianças com doença crônica.

\section{MÉTODOS}

Trata-se de uma investigação qualitativa. $\mathrm{O}$ cenário da pesquisa integrou dois Centros Hospitalares e um Agrupamento de Centros de Saúde, em Portugal.

Os sujeitos da pesquisa foram 20 mães de crianças com doença crônica. A colheita de dados foi realizada na residência das mães, no período de Julho de 2009 a Junho de 2010. A cada grupo atribuímos uma letra (A; B), designando-os de acordo com o cumprimento dos critérios de inclusão da amostra populacional: no grupo $\mathrm{A}$, pais recrutados no circuito de recorrência ao Hospital (Unidade de Urgência Pediátrica, Serviço de Pediatria, Consulta Externa de Pediatria)/Unidades de Cuidados de Saúde Personalizados (Consulta de Saúde Infantil e Juvenil), que não são membros activos de grupos de ajuda mútua. No grupo B foram incluídos pais recrutados no circuito dos encontros dos grupos de ajuda mútua, em idêntico número aos pais do grupo A. O número de participantes foi determinado pela totalidade dos pais contactados.

Recorreu-se à utilização de um instrumento de recolha de dados, organizado em duas partes distintas: caracterização sócio-demográfica e entrevista semi-estruturada (média de duração de 45 minutos), com vista à obtenção de dados para a elaboração do ecomapa e genograma de esperança, previamente representados num formulário construído para o efeito. Posteriormente, procedeu-se à análise de conteúdo das entrevistas, que permitiu a análise das narrativas expressas pelas mães em complementaridade à co-construção do genograma de esperança e do ecomapa.

Tratando-se de uma investigação que envolve seres humanos, foi realizado um protocolo de investigação aprovado pela Comissão de Ética em Saúde do Centro Hospitalar de Setúbal, E.P.E./Portugal, firmado em acta do Conselho de Administração n. ${ }^{\circ}$ 15/09. As mães envolvidas no estudo assinaram o termo de Consentimento Livre e Esclarecido antes da etapa de produção dos dados.

\section{RESULTADOS E DISCUSSÃO}

A utilização dos genogramas como instrumento de coleta de dados, nos estudos de natureza qualitativa, tem vindo a constar-se de grande 
utilidade, sobretudo, junto de famílias de crianças com doença crônica. ${ }^{25}$ Ao ser proposto um genograma de esperança, proporcionou-se a descoberta e a identificação dos fatores de desenvolvimento da esperança das mães de crianças com doença crônica, participantes no estudo.

Numa abordagem genuína, mas ainda rudimentar da esperança, enquanto construto teórico, esta foi explanada considerando as dimensões que a caracterizam. ${ }^{21}$ Destas, destacamos os componentes que estruturam a experiência da esperança: as mães participantes no estudo centraram-se no seu processo emocional e de espera, perante o prognóstico/evolução da sintomatologia associada à doença dos seus filhos (dimensão afetiva); na orientação de objetivos/metas em prol de uma gestão mais adequada do tratamento/acompanhamento (dimensão comportamental); no modo como traduziram a espera perante o futuro e interpretaram as suas experiências de vida pela iden- tificação dos padrões de interação em esperança com os distintos membros da família (dimensão contextual); nas histórias de esperança narradas e na respectiva expectativa da sua continuidade, tendo em conta o vivido, o momento atual e o que esperam do futuro (dimensão temporal); na identificação, apropriação dos seus atributos pessoais e recursos de esperança, tal como o envolvimento dos mesmos nos relacionamentos estabelecidos com a família (dimensão afiliativa); e, por fim, na interpretação das suas memórias moralizantes centradas na esperança e no desejar um melhor futuro (dimensão cognitiva).

\section{Identificação das histórias de esperança}

Da análise do genograma de esperança (representado na Figura 1), confirma-se a centralização dos padrões de interação de esperança na família nuclear, tal como a identificação dos recursos de esperança nos membros que a integram.

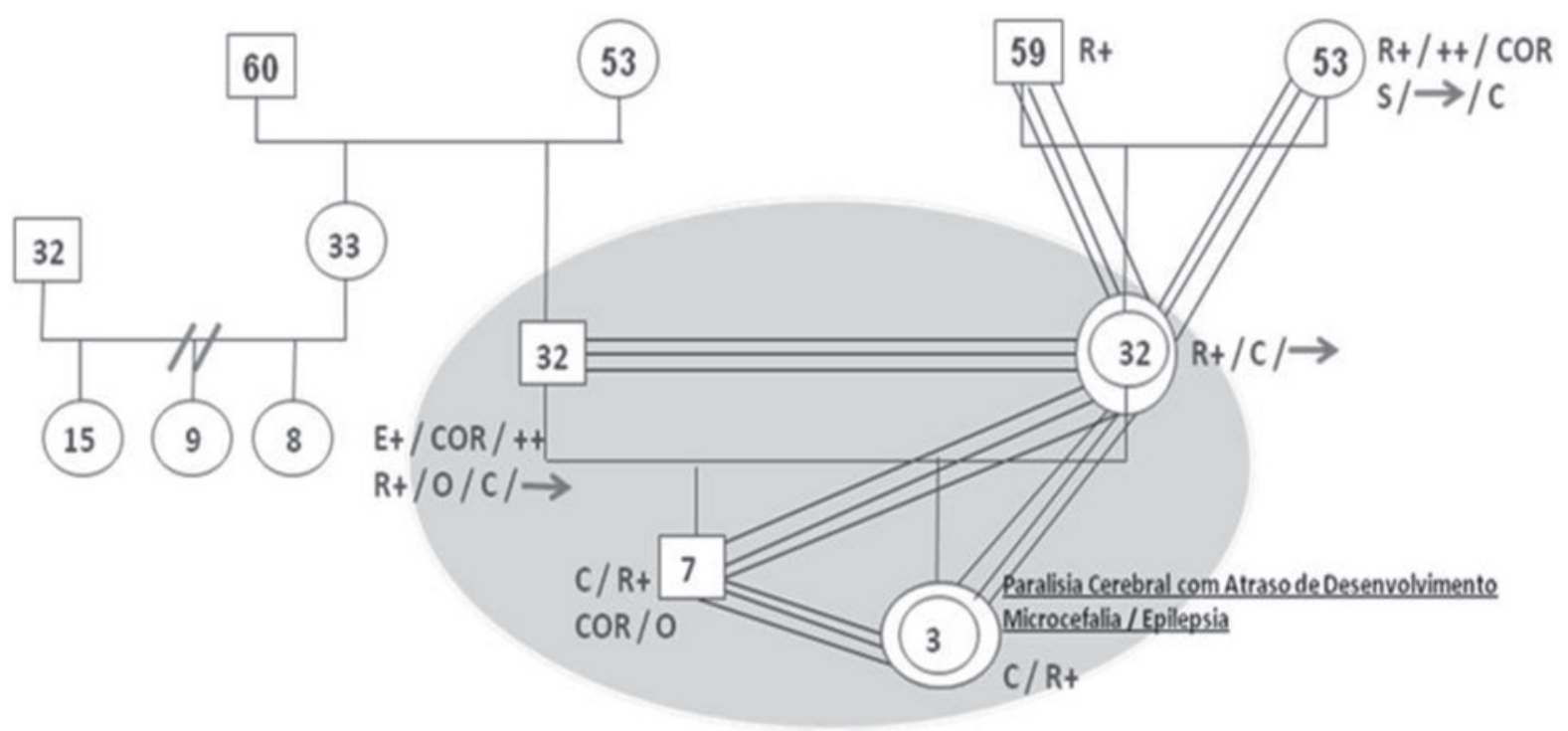

Figura 1 - Genograma de esperança da família A

A nível da avaliação da estrutura da família A, esta é completada pelos padrões de interação em esperança entre a Mãe A e o marido, enquanto casal (subsistema conjugal), entre os mesmos como pais (subsistema parental) e entre os seus filhos (subsistema fraternal). Foram identificados relacionamentos promotores de esperança entre os seguintes membros da família: avós maternos, casal e filhos. A ausência de interação com os outros membros prendeu-se, sobretudo, com o distanciamento geográfico e a ausência de ligação dos mesmos com a família nuclear. Contudo, tal não representa uma relação de ameaça à esperança, pois não foi caracterizada como unida e conflituosa na partilha, encorajamento e apoio emocional, ou referenciada como abandono e isolamento. Apesar do descrito, mantêm contatos esporádicos, desconhecendo no entanto as necessidades dos pais. Apesar de falarem connosco ao telefone, eles nem fazem ideia do que nós precisamos [...] não convivem diariamente com esta situação [...] eles dizem que a minha filha é assim e pronto [...] como se não houvesse mais nada para fazer (Mãe A).

A valorização dos atributos pessoais foi notoriamente responsável pela promoção da descrição de memórias moralizantes, reportadas às recordações de momentos felizes e prazerosos que a mãe viven- 
ciou junto do seu marido, filhos e pais. Dentre outros exemplos, os "momentos de respiro" só possíveis de ocorrerem pelo apoio que a sua mãe lhe disponibiliza a tempo inteiro. Estes momentos são citados como “[...] um espaço de tempo em que os pais não têm a responsabilidade de cuidar da criança, estando a mesma a ser cuidada por outros cuidadores[...]". 26:66 Este apoio permite ainda a manutenção da sua vida profissional, sentindo-se sustentada na gestão das limitações que a sua filha de três anos de idade apresenta, quer ao nível da partilha no cuidar da criança, quer na procura de recursos na comunidade.

Em continuidade, destacou na sua mãe, como atributos pessoais, a coragem no enfrentamento das dificuldades e retrocessos impulsionados pelas complicações inerentes à doença crónica da criança, o carinho e a serenidade, sobretudo nos momentos de partilha e orientação para o futuro. Tal como é demonstrado na figura 1, esta orientação foi citada também no casal, sendo determinante para o $\mathrm{em}$ powerment desta família, pois permite o estabelecimento de um plano de atividades e distribuição de tarefas, prevenindo o desgaste físico e mental por sobrecarga do cuidador: nós conseguimos muito bem distribuir tarefas [...] quando uns não estão avançam outros [...] e quando a minha filha está doente trocamos a vigília [...] num dia ficam uns acordados no outro dia há uma troca [...] (Mãe A).

A mãe enfatizou o carinho, a coragem e o otimismo no seu marido e no filho de 7 anos de idade: o meu filho compreende perfeitamente o que a irmã tem e adora a irmã por isso é muito carinhoso com ela [...] por outro ladoé um corajoso sobretudo quando vê a irmã com convulsões chegando até a ajudar-nos [...]. A professora do meu filho tem me contado que ele só celebra as coisas boas da irmã [...] quando por exemplo a irmã riu pela primeira vez [...] se não foi internada quando adoeceu [...] é um optimista [...] só vê as coisas boas [...] e isso dá-me muita força (Mãe A). Ao referir-se ao seu marido: [...] encara os desafios com muita energia [...] é um optimista e consegue sempre roubar um sorriso na filha [...] vê também sempre o melhor dos problemas e das dificuldades [...] (Mãe A). Por sua vez, a expressão da base espiritual, nesta família, foi percepcionada pela presença de crenças religiosas num dos membros do casal e na avó materna. Quanto aos recursos de esperança presentes no subsistema individual (na mãe A), a ancoragem na questão "o que tem aprendido de melhor sobre si com a doença da sua filha": [...] a coragem [...] o ser capaz de lutar e conseguir atingir o que for melhor para ela [...] a té porque há familias e pais com situações em casa bem piores (Mãe A). Perante o mencionado foi possível tecer as seguintes considerações: o subsistema conjugal é eficaz no estabelecer de metas e objetivos concretizáveis na resolução de situações perante a adversidade, o que lhes tem permitido prosperar com carinho, apoio e coesão. Significa que existe uma resiliência familiar bem sucedida, depreendida pela qualidade das interacções familiares e atitude optimista, continuando a família a amar e apoiar os seus membros mesmo perante os desafios inesperados. ${ }^{27}$

Da leitura do genograma representado na figura 2, depreende-se a existência de distintos padrões de interação em esperança para além dos identificados na família nuclear.

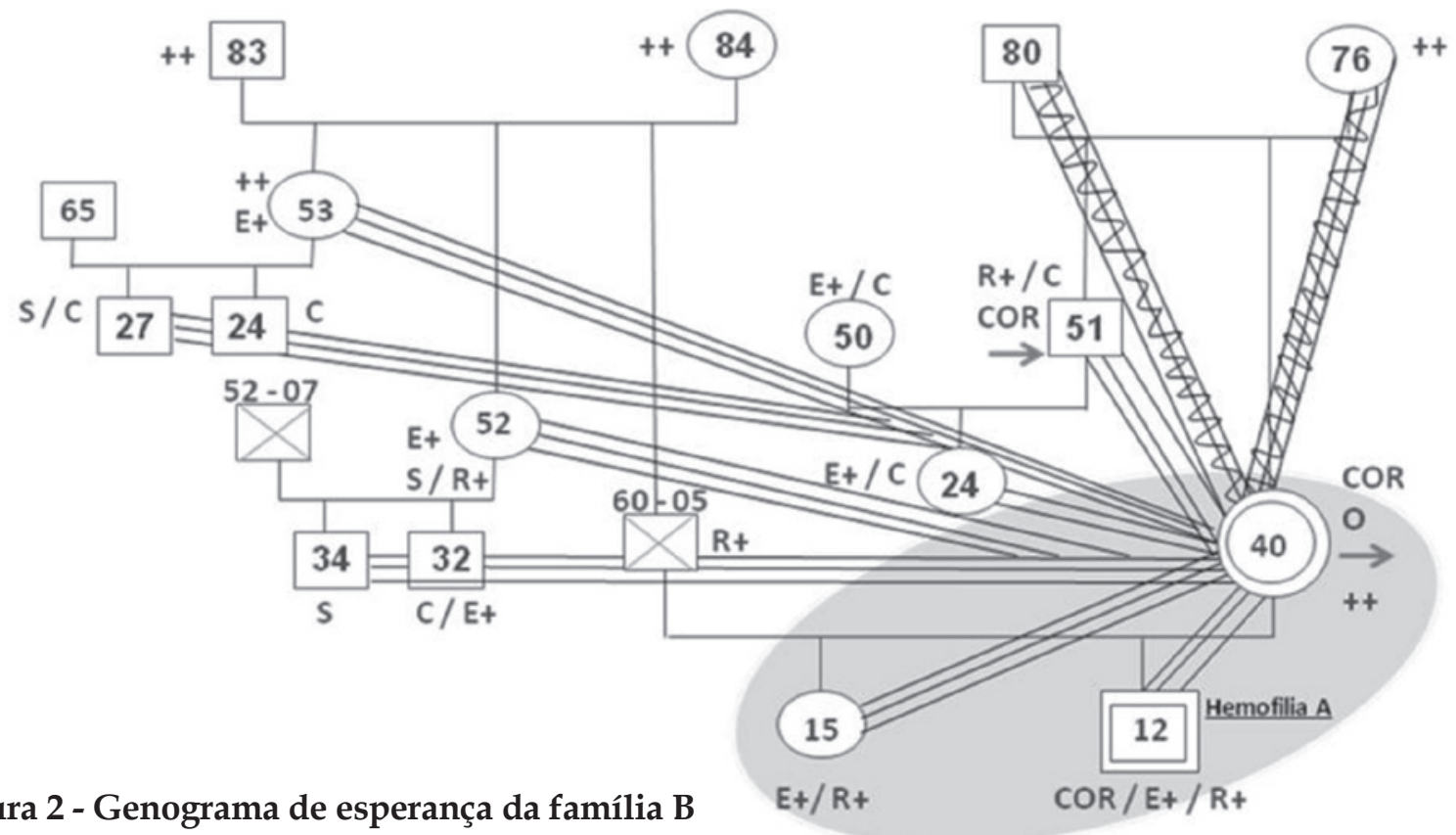

Figura 2 - Genograma de esperança da família B 
Maioritariamente, a mãe B identifica relações promotoras de esperança, exceto a descrita com a sobrinha de 24 anos de idade, que reside fora do País, caracterizada como uma relação com antecedentes de esperança. Trata-se de um membro da família que, no passado, estabeleceu uma relação muito forte na partilha, encorajamento e apoio emocional. Os atributos pessoais que a caracterizam são, essencialmente, a energia e o carinho que transmite, mesmo não residindo na mesma zona geográfica. “[...] os múltiplos vínculos de lealdade dos membros da família extensa podem ser invisíveis, mas são forças muito influentes na estrutura familiar. Relacionamentos e apoios especiais podem existir a grandes distâncias geográficas [...]". 1:75 Por sua vez, tratando-se de uma mãe que frequentou um programa de formação acerca de procedimentos relacionados com a administração de terapêutica endovenosa ao seu filho, no domicílio, em termos de atributos pessoais descreve-se como corajosa e otimista: [...] tem de ser [...] se não o conseguisse fazer seria tudo muito mais complicado...tinha de vir com ele ao hospital muitas vezes e não estaria tranquila nunca...sobretudo se the acontecesse alguma coisa e estivesse longe de quem lhe pudesse administrar o factor VIII (Mãe B). De igual modo, existe uma ligação com a base espiritual, associada à presença de crenças: eu acredito em Deus e nos momentos de maior aflição eu peço-lhe ajuda...mas não sou praticante apesar de ser católica [...] (Mãe B).

Considera o apoio que lhe é disponibilizado pelo seu irmão como imprescindível, sobretudo desde o falecimento do seu marido. Atribuiulhe tal como a si própria, o atributo pessoal de orientação para o futuro, no que se refere ao estabelecimento e posterior cumprimento de metas/objetivos. Sejam estes relacionados com os cuidados de saúde aos seus filhos, como no que diz respeito a situações quotidianas que carecem de uma planificação. A este nível, concordamos com a importância atribuída às alianças e natureza dos vínculos relacionais no "[...] capacitar a família a obter suas próprias forças e recursos para seus membros apoiarem-se uns aos outros $[\ldots]^{\prime \prime 1: 162}$, mesmo que as narrativas advenham da perspectiva de um dos pais ou de ambos.

Como relações de ameaça à esperança, descreveu as existentes com os seus pais: pensam logo o pior...é terrível...dou por mim a esconder deles as informações quando o meu filho adoece porque eles em vez de apoiarem fazem muitas questões e dramatizam tudo...a mim só me dificultam nas horas em que preciso de maior ajuda (Mãe B). Face ao exposto, relativamente à qualidade deste relacionamento, concluímos que o abandono e o isolamento que advêm do decorrer dos processos de tomada de decisão, estão correlacionados com o aumento da ansiedade dos seus pais quando confrontados com a adversidade. Num processo descrito em simultâneo, as estratégias de enfrentamento utilizadas por esta mãe coadunamse com o mencionado na literatura temática: a aceitação da doença do seu filho e o enfrentamento ativo da sintomatologia/complicações que a mesma implica, sobretudo pelo desenvolvimento das suas competências no manejo autonomo da terapêutica endovenosa, e na utilização do suporte emocional conferido pela sua família. ${ }^{28}$

\section{CONCLUSÕES}

Considerando o objeto da análise em foco nesse artigo, adotamos uma estreita ligação conceitual entre a esperança, a avaliação e a intervenção na família.

Independentemente dos cuidados que cada criança necessita, com maior ou menor dependência, as famílias são detentoras de uma estrutura e funcionamento próprios, cuja interpretação foi facilitadora de uma maior compreensão da dinâmica familiar em domínios da promoção de esperança.

A ênfase no seio da prática de enfermagem dos cuidados centrados na família como cliente, implica a integração de uma abordagem sistêmica. Esta premissa permitiu identificar os recursos de esperança disponíveis, bem como a natureza e qualidade dos vínculos relacionais no estabelecimento de padrões de interação em esperança.

Foi possível gerar espaços privilegiados de partilha com as mães participantes no estudo, que visaram a ampliação e a celebração das competências das famílias, enquanto recursos disponíveis para o desenvolvimento da sua esperança. A valorização das forças em vez das fraquezas, deficits e/ou dificuldades coadunaram-se com o descrito nos modelos de resiliência familiar. No que diz respeito aos recursos de esperança, estes contemplaram as crenças e as práticas religiosas, pelo que salientamos a importância que a religião assumiu nas famílias apresentadas nos genogramas de esperança.

Ressalvamos o carácter dinâmico do ecomapa, na análise da natureza e qualidade das relações estabelecidas entre as mães e os recursos da comunidade, tendo sido destacado a este nível o papel dos membros da família integrantes do 
sistema familiar ou da família alargada, no apoio aos pais como um recurso de esperança.

Em prol da qualidade dos cuidados que os pais/família prestam no domicílio à criança com doença crônica, e a par de uma planificação colaborativa de estratégias promotoras de esperança, é possível conferir reciprocidade à promoção do seu bem-estar. Depreendemos que a utilização de instrumentos de avaliação familiar, como o genograma de esperança e o ecomapa, têm uma importante aplicabilidade na assistência de enfermagem, por conferirem maior aproximação e abertura relacional, à interpretação dos padrões de interação e recursos de esperança existentes no sistema familiar. Sobretudo, em contextos de risco, agudizações da doença crônica da criança e/ ou nos processos de aprendizagem/acompanhamento, ao assumirmos e valorizarmos a família como alvo dos cuidados.

No contexto em questão, considerando que todas as famílias possuem forças e recursos, destacam-se os pontos fortes que permitem aos seus membros lidarem com os desafios e mudanças impostas pela doença da criança: traços que residem num indivíduo (por exemplo: coragem e otimismo) e/ou competências nos cuidados parentais.

Da premissa que a vivência de uma doença crônica pode colocar em risco a coesão e a adaptação do sistema familiar, propõe-se a utilização/atualização dos genogramas de esperança como forma de reconhecer um apoio efetivo e continuado.

\section{REFERENNCIAS}

1. Wright LM, Leahey M. Enfermeiras e famílias. um guia para avaliação e intervenção na família. São Paulo (SP): Roca; 2002.

2. Wright LM. Espiritualidade, sofrimento e doença. Coimbra (PT): Ariadne Editora; 2005.

3. Hanson SMH. Enfermagem de cuidados de saúde à família: uma introdução. In: Hanson SMH. Enfermagem de cuidados de saúde à família. teoria, prática e investigação. Loures (PT): Lusociência; 2005. p. 3-37.

4. Alarcão M. (Des) Equilíbrios familiares. Coimbra (PT): Quarteto; 2006.

5. Butler JF. The family diagram and genogram: comparisons and contrasts. Am J Fam Ther. 2008 May; 36(3):169-80.

6. Krüger LL, Werlang BSG. O Genograma como recurso no espaço conversacional terapêutico. Aval Psicol. 2008 Dez; 7(3):415-26.

7. Lowe R. Family therapy. $1^{\mathrm{a}}$ ed. London(UK): Sage Publications; 2004.
8. Brás S. Um olhar positivo na terapia familiar: a utilização do contexto terapêutico como forma de salientar as competências da famílias [página da internet]. 2005 [acesso 2010 Nov 12]. Disponível em: http:/ / www.psicologia.com.pt/artigos/textos / A0381.pdf

9. Frame MW. The spiritual genogram in family therapy. J Marital Fam Ther. 2000 Apr; 26(2):211-6.

10. Hodge DR. Developing a spiritual assessment toolbox: a discussion of the strengths and limitations of five different assessment methods. Health Soc Work. 2005 Nov; 30(4):314-23.

11. Cutcliffe JR, Grant G. What are the principles and processes of inspiring hope in cognitively impaired older adults within a continuing care environment?. J Psychiatr Ment Health Nurs. 2001 Oct; 8(5):427-36.

12. Miller JF. Hope: a construct central to nursing. Nurs Forum. 2007 Jan-Mar; 42(1):12-19.

13. Stephenson $C$. The concept of hope revisited for nursing. J Adv Nurs. 1991 Dec; (16):1456-61.

14. Nurses IC. Classificação internacional para a prática de enfermagem: Versão 1.0. Lisboa (PT): Ordem dos Enfermeiros; 2006.

15. McDermott D, Snyder CR. Making hope happen: a workbook for turning possibilities into reality. Oakland(US): New Harbinger Publicatons, Inc; 1999.

16. Di Primio A, Schwartz E, Bielemann V, Burille A, Zillmer J, Feijó A. Rede social e vínculos apoiadores das famílias de crianças com câncer. Texto Contexto Enferm. 2010 Abr-Jun; 19(2):334-42.

17. Herth K. Fostering hope in terminally-ill people. J Adv Nurs. 1990 Nov; 15(11):1250-9.

18. Buckley J, Herth K. Fostering hope in terminally ill patients. Nurs Stand. 2004 Nov; 19(10):33-41.

19. Herth KA, Cutcliffe JR. The concept of hope in nursing 3: hope and palliative care nursing. Br J Nurs. 2002 Jul 25-Aug 7;11(14):977-83.

20. Editora P. Dicionário escolar da língua portuguesa. Porto (PT): Porto Editora; 2009.

21. Entralgo PL. La espera y la esperanza: historia y teoria del esperar humano. Madri (ES): Alianza Editorial; 1984.

22. Bassett H, Lloyd C, Tse S. Approaching in the right spirit: spirituality and hope in recovery from mental health problems. Int J1 Ther Rehabil. 2008 Jun; 15(6):254-9.

23. Snyder CR. Handbook of hope. theory, measures, and applications. London (UK): Academic Press; 2000.

24. Trepper TS, Dolan Y, McCollum EE, Nelson T. Steve de shazer and the future of solution-focused therapy. J Marital Fam Ther. 2006 Apr; 32(2):133-139.

25. Wendt NC, Crepaldi MA. A utilização do genograma como instrumento de coleta de dados na pesquisa qualitativa. Psico Reflex Crít. 2008; 21(2):302-10. 
26. Charepe ZB. O Encontro com a ajuda mútua: percepções dos pais de crianças com doença crónica [tese]. Lisboa (PT): Universidade Aberta, Mestrado em Comunicação em Saúde; 2006.

27. Black K, Lobo M. A conceptual review of family resilience factors. J Fam Nurs. 2008 Feb; 14(1):33-55.
28. Wong MG, HeriotSA. Parents of children with cystic fibrosis: how they hope, cope and despair. Child Care Health Dev. 2008 May; 34(3):344-54.

29. MvGoldrick M, Gerson R. Genograms in family assessment. Nova Iorque (US): WW. Norton \& Company; 1985. 
ANEXO 1

\section{Codificação do Genograma de Esperança}

Simbologia de um Genograma ${ }^{3,29}$
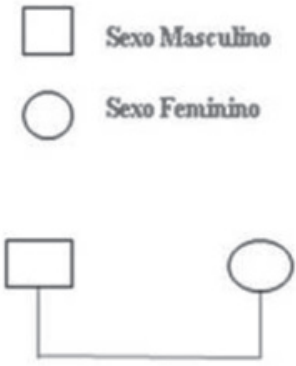

C: CASAMENTO
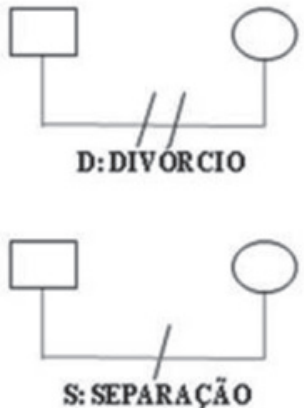
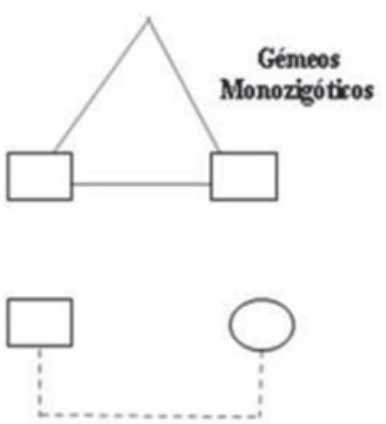

Vivendo juntos uma rehąäo ou ligarä̃o

Padrões de Interacção em Esperança ${ }^{12,10}$

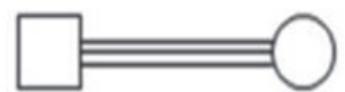

Reka̧̧äo promotora de esperança

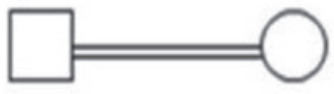

Rebção com antecedentes de esperança

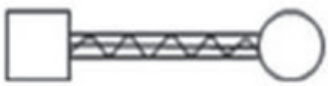

Rehçäo de ameaça à esperança

Recursos de Esperança ${ }^{12,10}$

$\begin{array}{lll}\text { Atrhutos Pessoais } & \text { COR: Coragem } & \text { S : Serenidade } \\ & \text { C : Carinh } & 0: \text { Optimismo } \\ & \text { L+ : Energia } & \rightarrow \text { : Orientaçăo para o futuro }\end{array}$

Memórins Moralizantes R+: Recordaçöes momentospositivivos

Base Espiritual

H: Presença decrenças epráticas expirituais

Portuguesa

Edifício da Biblioteca João Paulo II - $5^{\circ}$ piso

1649-023 - Palma de Cima, Lisboa, Portugal

E-mail: zaidacharepe@ics.lisboa.ucp.pt 